\section{СПИСОК ЛИТЕРАТУРЫ:}

1. Об образовании в Российской федерации: федер. закон № 273-Ф3 от 29.12.2012: по сост. на 01.09.2013. URL: http://www.zakonrf.info/zakon-ob-obrazovanii-v-rf.

2. Закон України «Про вищу освіту» № 1556-VII: остання редакція від 01.01.2015. URL: http://docs.dtkt. ua/ua/doc/1204.353.0 (дата обращения: 19.06.2015).

3. Эстетика: словарь / под общ. ред. А.А. Беляева и др. М.: Политиздат, 1989. 447 с.

4. История эстетики: памятники мировой эстетич. мысли: в 7 т. / гл. ред. М.Ф. Овсянников. М.: Искусство, 1962. Т. 2: Эстетические учения XVII-XVIII веков. $1964.835 \mathrm{c}$.

5. Мастера искусства об искусстве: избр. отрывки из писем, дневников, речей и трактатов : в 7 т. / под. общ. ред. А.А. Губера. М.: Искусство, 1965. Т. 5: Искусство конца XIX - начала XX века. / под ред. И.Л. Маца и Н.В. Яворской. 1969. Кн. 2.541 с.
6. Локк Д. Избранные философские произведения: в 2 т. М.: Соцэкгиз, 1960 Т. 1: [Опыт о человеческом разуме]. $1960.734 \mathrm{c}$.

7. Лосев А.Ф., Шестаков В.П. История эстетических категорий. М.: Искусство, 1965. 374 с.

8. Чернышевский Н.Г. Статьи по эстетике. М.: Соцэкгиз, $1938.316 \mathrm{c}$.

9. Хатчесон Ф., Юм Д., Смит А. Эстетика. М.: Искусство, 1973. 478 с.

10. Руссо Ж.-Ж. Об искусстве: ст. высказывания, отрывки из произведений / пер. с фр. и вступ. ст. Т.Э. Барской. Л.; М.: Искусство, 1959. 296 с.

11. Кант И. Сочинения: в 6 т. М.: Мысль, 1964. Т. 5: Сочинения по эстетике: критика способности суждения / под общ. ред. В.Ф. Асмуса, А.В. Гулыги, Т.И. Ойзермана. $1964.543 \mathrm{c}$.

12. Столович Л.Н. Природа эстетической ценности. М.: Политиздат, 1972. 272 с.

\title{
ORIGINS OF THE CONCEPT OF TASTE AS THE BASIS FOR FORMING ARTISTIC TASTE OF ART STUDENTS
}

\section{M.Yu. Birukov, associate professor of the Chair of Design and Project Technologies} Luhansk State University, Luhansk (Luhansk People's Republic)

Abstract. Implementation of the principles of democracy, humanitarian priorities in the higher vocational education determines profound changes in the formation of artistic taste of contemporary young people. The problem of the formation of art taste and personality is complex, ambiguous and examined by representatives of different sciences. The artistic taste is the focus of aesthetic evaluation criteria of all spheres of human activities, it serves as a basis for establishing the invariant personality-the unique forms of the individual's behavior, thinking and creativity. This article examines the history, state and value of artistic taste in the formation of human personality in the historical and modern science, distinguishes between subjective and objective views on the conditions for the existence and formation of artistic taste, works out a definition of artistic taste at the present stage of society development. The variety of artistic tastes is explained by the unlimited richness of art objects themselves, as well as the constant development of reality - and, above all, social reality - by the emergence of new conditions of life, development of man and man-made objects. The question of the diversity of artistic tastes finds its solution, first of all, while considering the objectivity of their content; the variety of specific manifestations of beauty accounts for diverse taste preferences. Individual display of artistic taste is valuable in demonstrating the nuances of the qualities of the object and allows one to pass on to others the feeling one experienced. Thus, a foundation is laid for creative evaluating interaction, so the artistic taste serves as an effective means of aesthetic education of art students in the course of vocational training.

Keywords: aesthetic taste, artistic taste, aesthetic consciousness, art education, art students, teaching process, aesthetic training.

УДК 378.147 .88

\section{ОНЛАЙН РЕСУРСЫ ИКТ В РЕАЛИЗАЦИИ ФГОС ВО ПО НАПРАВЛЕНИЮ ПОДГОТОВКИ 44.03.01 ПЕДАГОГИЧЕСКОЕ ОБРАЗОВАНИЕ} (C) 2016

М.А. Воронина, старший преподаватель

кафедры информационно-коммуникационных технологий в образовании

Самарский государственный социально-педагогический университет, Самара (Россия)

Аннотация. В статье рассматриваются актуальные вопросы, связанные с использованием информационнокоммуникационных технологий в процессе современного образования. Анализируются требования Федеральных государственных образовательных стандартов начального, основного и высшего образования. Акцентируется внимание на необходимости формирования ИКТ-компетентности на всех ступенях образования. Речь идет о концепциях применения информационно-коммуникационных технологий в школе. Анализируется понятие «информатизация образования».

Рассматривается профессиональный стандарт педагога и описывается трехуровневая модель формирования ИКТ-компетентности педагога. Проводится анализ возможностей проведения интерактивных лекций на основе поддержки социальных сетей или использования облачных технологий.

В статье предлагается использование метода конкретных ситуаций в виртуальной реальности, как средства формирования требуемых компетенций и повышения мотивации студентов. Анализируется дидактический по- 
тенциал сетевых педагогических сообществ как основы для непрерывного самообразования. Приводится опыт применения интернет-сообществ как площадки проведения научного педагогического исследования. Предлагается использование видеоконференций как инструмента повышения квалификации, анализируется сервис Google Hangouts.

Делается вывод о необходимости педагогам высшей школы использовать современные информационные технологии в процессе образования, что дает возможность перенести обучение за стены образовательного учреждения. Такое образование будет отвечать не только российским стандартам жизни, но и мировым.

Ключевые слова: ФГОС, бакалавриат, высшее профессиональное образование, образовательные результаты, технологии образования, информационно-коммуникационные технологии, компетентность, инновационная деятельность.

В настоящее время общество встало на путь кардинальных социально-экономических преобразований, которые затронули все сферы общественной жизни. Несомненно, они коснулись и сферы обучения и воспитания будущего поколения. Исследования, посвященные теории и практике обучения неотрывно связаны с поиском приемов и методов модернизации учебновоспитательного процесса, отвечающих новым требованиям, которые предъявляет государство и общество в целом [1-16]. Одной из самых важных сфер человеческой деятельности постепенно становится образование. Перспективы экономического и духовного развития общества определяются способностью системы образования отвечать потребностям общества в высококачественных образовательных услугах.

Развивающемуся обществу нужны образованные, нравственные, конкурентоспособные на рынке труда специалисты, которые могут самостоятельно принимать решения в ситуации выбора, способные к сотрудничеству, отличающиеся мобильностью, конструктивностью, готовые к межкультурному взаимодействию и инициативным преобразованиям. Новые требования не могли не сказаться на сфере образования.

Основной целью современного образования является развитие личности школьника. Необходимо ввести его в образовательную среду, познакомить с её духовной, нравственной и культурной реальностью. Педагогу необходимо помочь школьнику сформироваться именно как личности в соответствии с его возможностями, склонностями, задатками. Все это невозможно реализовать без благоприятных образовательных условий.

Процесс усвоения знаний и умений, с одной стороны, индивидуален, специфичен для каждого школьника, с другой стороны, является объективным, имеющим общие характеристики для одинаковых по возрасту обучающихся. Общность механизма усвоения (интериоризации) знаний и умений позволила психологам (Л.С. Выготскому, П.Я. Гальперину, Н.Ф. Талызиной и др.) выявить его закономерности. Одной из важнейших закономерностей является следующая: только в процессе деятельности происходит интериоризация нового, причем, чем активнее деятельность, тем успешнее усвоение материала. Это означает, что педагогу необходимо формулировать результаты образования как результаты деятельности учеников, а для получения запланированных образовательных результатов он должен уметь организовывать активную деятельность школьников.

Основными результатами образования согласно федеральным государственным образовательным стандартам общего образования, являются универсальные учебные действия (УУД), формирование которых является одним из условий социализации школьника [17, 18]. Выделяются личностный, коммуникативный, регу- лятивный и познавательный блоки УУД. Для успешного формирования УУД у школьников учителю необходимо представлять сам спектр формируемых УУД, их структуру, психологические закономерности формирования, способы педагогического управления деятельностью обучающихся в процессе овладения УУД и, в соответствии с этими, теоретическими положениями подбирать методические средства и предметное содержание, наиболее благоприятное для формирования того или иного вида УУд.

Так, в федеральном государственном образовательном стандарте начального общего образования отмечена необходимость формирования ИКТ компетентности обучающихся, а именно ребенок, освоивший основную образовательную программу начального общего образования должен активно использовать средства информационных и коммуникационных технологий для решения коммуникативных и познавательных задач [17]. В федеральном государственном образовательном стандарте основного общего образования также отмечается необходимость формирования и развития у учащихся компетентности в области использования ИКТ [18]. К тому же, в Примерную основную образовательную программу основного общего образования как важнейший междисциплинарный компонент входит программа развития универсальных учебных действий, включающая формирование компетенций обучающихся в области использования информационнокоммуникационных технологий; сформулирован перечень ИКТ-компетенций школьников, описано содержание, виды и формы организации учебной деятельности по развитию информационно-коммуникационных технологий [19]. Образовательная организация должна обеспечивать условия материально-технические и кадровые реализации этой междисциплинарной программы, понимая ее значимость для самоопределения школьника и его социализации.

Таким образом, компьютер в школе выступает не только как объект изучения, но и как дидактическое (для педагога) и инструментальное (для учащихся) средство обучения.

На наш взгляд, использование информационных технологий в учебном процессе, наиболее полно удовлетворяет его требованиям и максимально приближает процесс обучения к реальным условиям.

Рассмотрим определение понятия «информационная технология». Л.О. Рупакова определяет понятие информационная технология обучения как дидактический процесс с применением целостного комплекса компьютерных и других средств обработки информации, позволяющей на системной основе организовать оптимальное взаимодействие между преподавателем и обучающимся с целью достижения гарантированного педагогического результата [20]. На практике такими 
технологиями называют все, которые используют технические информационные средства.

С помощью использования инновационных информационных технологий можно повысить качество образовательных результатов обучающихся, творческую и интеллектуальную составляющие учебной деятельности; самоконтроль, адаптировать обучение к индивидуальным особенностям школьников.

Внедрение в образовательный процесс информационных технологий получило название «информатизация образования». В педагогическом энциклопедическом словаре информатизация образования определяется как процесс обеспечения образования методологией и практикой разработки и оптимального использования информационных технологий, ориентированный на реализацию всех целей обучения и воспитания [21].

К проблеме информатизации образования обращались многие ученые: А.П. Ершов, Д.В. Чернилевский, М.Ю. Бухаркина, А.Е. Петров, М.В. Моисеева, Г.Д. Громов, Л.П. Халяпина и многие другие [22-26]. Теоретической основой всех последующих исследований является концепция информатизации образования А.П. Ершова - формирование компьютерной грамотности как элемента общеобразовательной подготовки человека [21].

Позже стала преобладать концепция, согласно которой основными направлениями информатизации образования являются:

- повсеместное освоение информационными технологиями;

- проведение исследований по использованию информационных технологий в процессе обучения и воспитания.

Таким образом, информационные технологии становятся неотъемлемой частью обучения и воспитания, они открывают новые технологические варианты обучения, связанные с уникальными возможностями современных технологий.

При применении информационных технологий в процессе образования разумно подразделить их на две группы:

- технологии, ориентированные на локальные компьютеры (компьютерные технологии);

- технологии, ориентированные на локальные сети и глобальную сеть Интернет (телекоммуникационные технологии) [27].

Первые - готовые программы, компьютерные проектные среды, электронные задачники и учебники, и другие дидактические материалы. Вторые - образовательные онлайн ресурсы, дистанционные уроки, видеоконференции, видео-уроки, онлайн презентации и многое другое. В нашем исследовании мы считаем целесообразным рассматривать оба вида информационных технологий.

Что касается психолого-педагогического аспекта применения информационных технологий, то данные вопросы достаточно разработаны. О.К. Тихомиров и Л.Н. Бабанин рассматривали проблемы использования информационных технологий при обучении и воспитании, и связанные с этим процессы изменения мышления [28]. Исходя из анализа исследований можно сделать вывод о том, что применение информационных технологий способствует:

- обогащению восприятия учебного материала;
- усилению мотивации обучения;

- активизации к самообучению, самоактуализации, самовоспитанию, самореализации;

- формированию теоретического мышления;

- формированию творческого и критического мышления;

- развитию образного мышления;

- индивидуализации обучения.

Исходя из вышесказанного, информационные технологии не просто можно, а необходимо применять в школе, однако при этом возникает проблема: использование информационно-образовательной среды в школе требует у сотрудников образовательной организации такого уровня ИКТ-компетентностей, который позволит им решать перечисленные профессиональные задачи, что накладывает определенные требования к выпускникам педагогических вузов.

Именно поэтому в профессиональном стандарте педагога отмечено, что сформированность ИКТкомпетентности является необходимым условием для выполнение трудовых функций учителя. Причем в стандарте выделяется трехуровневая система ИКТкомпетентности педагога: общепользовательская, общепедагогическая и предметно-педагогическая [29]. При этом первый этап - развитие ключевых компетентностей использования ИКТ, на втором - использование ИКТ для решения некоторых профессиональных задач, формируется базовая компетентность на основе ключевой, на третьем этапе - формируется специальная компетентность на основе базовой, т.е. учитель овладевает предметно-ориентированными средствами ИКТ для решения всех профессиональных задач.

И, соответственно, необходимость формирования ИКТ-компетентностей будущих учителей отражена в федеральном государственном образовательном стандарте высшего образования по направлению подготовки 44.03.01 Педагогическое образование (ФГОС ВО). Согласно ФГОС ВО, выпускник, освоивший программу бакалавриата, должен быть готов к использованию технологий, которые соответствуют возрастным особенностям обучающихся; формированию образовательной среды с применением ИКТ; а также непрерывно повышать уровень своего образования путем самообразования. Роль информационных технологий в осуществлении данных требований переоценить сложHо.

Таким образом, высшая школа должна обеспечить готовность будущего учителя к владению средствами ИКТ и использованию их в профессиональной деятельности. Следовательно, должны измениться требования к дидактике высшей школы. В учебнометодических пособиях [30,31,32], посвященных этому вопросу значительное внимание уделяется таким технологиям как метод конкретных ситуаций, проектный метод, деловая игра, дискуссия, портфолио, квесты и пр. [33-37]. Однако в публикациях практически отсутствует описание аппаратного и программного обеспечения вышеуказанных технологий. В то же время, существует мнение [38], что одним из эффективных способов сопровождения педагогического процесса могут стать облачные технологии.

Современные студенты - это активные пользователи всевозможных гаджетов: планшеты, телефоны, нетбуки и ноутбуки являются неотъемлемой частью жизни 
современной молодежи. Казалось бы, чем преподаватели высшей школы могут их удивить? Как показывает практика, стандартные формы обучения (лекции, семинарские занятия) постепенно вытесняются современными (интерактивными лекциями, смешанным обучением). Студентам отводится роль активных субъектов образовательного процесса, а не пассивных слушателей. Простая лекция в таких условиях (когда с помощью гаджетов студент имеет практически неограниченный доступ к образовательному контенту) будет совершенно не эффективна. Гораздо результативнее (в плане формирования компетенций студентов) будет проведение лекции, основанной на технологии перевернутого обучения, когда студенты заранее проводят анализ проблемы с помощью различных ресурсов сети Интернет, а в ходе занятия организуется активное ее обсуждение, уточняются ключевые вопросы. Преподаватель может модерировать процесс подготовки к занятиям, организуя сетевую дискуссию посредством совместной работы в облачных документах, публикуя и обсуждая материалы в блоге, используя ресурс (группы, мероприятия и т.п.) социальных сетей (VK, Facebook, Google+).

С помощью современных средств информационнокоммуникационных технологий качественно может быть изменено представление о формах и приемах организации семинарских занятий. Что может быть интереснее полного погружения в реальную ситуацию? Так, например, в ходе использования метода кейс-стади бакалавры должны провести анализ ситуации - определить проблемы и предложить пути их решения, выбирая при этом наиболее приемлемый. Использование данного метода позволяет подготовить будущих учителей к решению профессиональных задач. Современные технологии позволяют, например, перенести ситуации в виртуальную 3D реальность, используя программу Second life, где созданные и управляемые студентами персонажи будут выполнять образовательные задачи. Применить данный метод на практике позволит технология BYOD (принеси свое устройство - bring your own device), когда каждый студент использует на занятии свой гаджет с установленной и настроенной программой.

Помимо готовности к педагогической деятельности, ФГОС ВО одним из образовательных результатов бакалавра по направлению «Педагогическое образование» определяет способность самостоятельно приобретать и использовать, в том числе с помощью информационных технологий, новые знания и умения. Это органично вписывается в концепцию «обучение через всю жизнь». Уникальным потенциалом для профессионального самосовершенствования являются сетевые профессиональные сообщества.

Например, участвуя в работе сетевых профессиональных сообществ («Открытый класс», «Образовательная галактика Intel», «Nachalka.com» и др. [29]), студент получает уникальный опыт взаимодействия с работающими учителями, методистами, специалистами органов управления образованием, учеными и т.п. Как правило, в таких сообществах обсуждаются актуальные проблемы современной системы образования: от установок нормативных документов до частных методик. Именно сетевые сообщества сегодня могут рассматриваться как альтернатива существующей формальной системе повышения квалификации. И задача высшей школы интегрировать выпускника в подобного рода профессиональную среду.
В частности, в сетевых педагогических сообществах существует уникальная практика проведения тематических вебинаров. Этот опыт сегодня легко транслируется в высшую школу. Так, например, сервис Google Hangouts позволяет проводить вебинары совершенно бесплатно. Кроме того, в процессе вебинара можно организовать обсуждение вопросов (голосовой и текстовый чат); выступающий может продемонстрировать заранее подготовленную презентацию, документ или даже видео. Трансляция вебинара может идти как в «прямом эфире» (с открытым доступом в сети Интернет), так и в приватном. При желании видеовстречу можно также записать и разместить на видеохостинге.

Неоценимым преимуществом участия в сетевых сообществах, является возможность апробации научнопрактических исследований, проведение их общественно-профессиональной экспертизы.

Практика показывает, что использование всех вышеуказанных технологий в процессе подготовки будущих бакалавров по направлению подготовки «Педагогическое образование» помимо формирования навыков использования ИКТ способствует формированию профессиональных навыков педагога, а также положительно влияет на мотивацию студентов, что позволяет добиваться более качественных образовательных результатов.

Таким образом, на современном этапе развития образования перед преподавателями высшей школы стоит сложная задача по выбору средств и технологий достижения планируемых результатов обучения. Преподавателю сегодня необходимо идти в ногу со временем, быть с современным поколением на одном уровне по использованию различных девайсов, т.к. внедрение информационных технологий в учебный процесс позволяет оперативно предоставлять и использовать необходимые учебно-методические материалы и организовывать учебный процесс, построенный с использованием различных форм и методов обучения не только в стенах образовательного учреждения, но и за его пределами. Необходимо на своем примере непрерывно показывать будущим учителям, как привычные им гаджеты и ресурсы сети Интернет можно использовать в образовательных целях. Такое образование можно в полной мере назвать современным и продуктивным, отвечающим не только российским, но и мировым стандартам развития общества.

\section{СПИСОК ЛИТЕРАТУРЫ:}

1. Федорова Ю.В., Невская О.В. Современные стандарты ИКТ-компетентности учителя математики // Стандарты и мониторинг в образовании. № 1. 2015. C. 56-61.

2. Кочетова Т.Н. Современные технологии математической подготовки будущего инженера // Вестник Самарского государственного технического университета. 2014. № 2 (22). С. 102-107.

3. Тараканова Е.Н., Брыксина О.Ф. ИКТ-компетентность как ключевой компонент профессиональной подготовки современного специалиста // Актуальные задачи современной науки и образования: теоретические и прикладные аспекты Сборник научных трудов по материалам Международной научно-практической конференции. 2015. С. 76-77.

4. Левченко В.В. Интегрированный подход к профессионально-педагогической подготовке в вузе спе- 
циалистов для образовательных учреждений: дис. ... дра. пед. наук: 13.00.08. Самара, 2009. 516 с.

5. Воронина М.А., Кочетова Н.Г., Осадченко И.И. Инновационные технологии обучения иностранным языкам в процессе подготовки будущих экономистов // Эволюция теории и практики современного образования: реалии и перспективы: Материалы Третьего Международного Педагогического Форума / отв. редактор С.А. Севенюк. Самара: ПГСГА, 2014. С. 44-48.

6. Современные технологии обучения в вузе (опыт НИУ ВШЭ в Санкт-Петербурге): Методическое пособие / под ред. М.А. Малышевой. СПб.: 2011. 134 с.

7. Богданова А.В., Глазова В.Ф. Реализация проектной технологии в обучении студентов гуманитарных направлений подготовки с использованием современных технологий // Карельский научный журнал. 2015. № 1 (10). С. 34-36.

8. Третьякова Е.М., Одарич И.Н. Повышение познавательной активности студентов в профессиональном обучении с применением новых информационных технологий // Азимут научных исследований: педагогика и психология. 2014. № 4. С. 123-125.

9. Кондаурова И.К., Захарова Т.Г., Гусева М.А. Региональный опыт подготовки и профессионального становления будущих педагогов-математиков в условиях модернизации среднего и высшего математического образования // Балтийский гуманитарный журнал. 2014. № 4. С. 81-84.

10. Ефремкина И.Н. Инновационные методы обучения как средство активизации познавательной деятельности студентов (на примере психологии) // XXI век: итоги прошлого и проблемы настоящего плюс. 2015. T. 1. № 6 (28). С. 74-80.

11. Прыскина Е.А. Место общего образования в образовании будущих педагогов // Азимут научных исследований: педагогика и психология. 2014. № 4. С. 97-99.

12. Кучай А.В. Интеграция мультимедийных технологий в процесс обучения // Балтийский гуманитарный журнал. 2014. № 4. С. 85-87.

13. Зуева С.В., Кривоногов С.В. Аспекты и перспективы развития современных информационных технологий // Карельский научный журнал. 2015. № 3 (12). C. $10-12$.

14. Кондаурова И.К. Подготовка будущих учителей к реализации дополнительного образования детей в контексте требований профессионального стандарта «педагог дополнительного образования детей и взрослых» // Азимут научных исследований: педагогика и психология. 2015. № 3 (12). С. 22-24.

15. Ванюхина Н.В. Компьютерные технологии и интернет в современном образовании // Карельский научный журнал. 2015. № 4 (13). С. 5-8.

16. Хасия Т.В. Педагогические инновационные технологии в вузе // Актуальные вопросы современной педа-гогики: материалы междунар. науч. конф. (г. Уфа, июнь 2011 г.). Уфа: Лето, 2011. С. 120-122.

17. Федеральный государственный образовательный стандарт начального общего образования [Электронный ресурс] Режим доступа: http://goo.gl/h8N2sR.

18. Федеральный государственный образовательный стандарт основного общего образования [Электронный ресурс] Режим доступа: http://goo.gl/1f2MH7.

19. Примерная основная образовательная программа основного общего образования [Электронный ресурс] Режим доступа: http://goo.gl/yOzbGZ.
20. Рупакова Л.О. Компьютерные технологии как средство развития познавательного интереса учащихся основной школы на занятиях по математике: (На примере решения арифмет. задач с элементами историзма): Дис... канд. пед. наук: Спец.13.00.02 - теория и методика обучения и воспитания (математика). М.: МПГУ, 2007. $210 \mathrm{c}$.

21. Педагогический энциклопедический словарь / гл. ред. Б.М. Бим-Бад. М.: Большая рос. энцикл., 2002. $528 \mathrm{c}$.

22. Белашов П.Д., Разуваев И.С. Понятие «компьютерные технологии» в рамках информационных технологий в обучении // XXI век: итоги прошлого и проблемы настоящего плюс. 2015. Т. 1. № 6 (28). С. 54-60.

23. Кривоногов С.В., Петров В.А. Применение информационных технологий в обучении как средство повышения качества образования // Карельский научный журнал. 2015. № 3 (12). С. 15-19.

24. Третьякова Е.М. Роль информационных технологий в реформировании образования // Балтийский гуманитарный журнал. 2015. № 1 (10). С. 148-149.

25. Сергушина О.В., Евсеева О.А. Информационное обеспечение учебной деятельности студентов вуза по педагогике: постановка проблемы // Азимут научных исследований: педагогика и психология. 2014. № 4. С. $112-113$.

26. Сальников И.И. Интеграционные процессы в развитии средств реализации информационных потребностей человека на современном этапе // XXI век: итоги прошлого и проблемы настоящего плюс. 2014. № 3 (19). С. 11-15.

27. Гайнуллина Ф.К. Использование телекоммуникаций в школе [Электронный ресурс] Режим доступа: http://www.eidos.ru.

28. Психологический анализ деятельности человека в Интернете / О. Тихомиров, Л. Бабанин, И. Белавина и др. // Информационный бюллетень РФФИ. 1999. Т. 7, № 6. С. $46-46$.

29. Профессиональный стандарт «Педагог (педагогическая деятельность в сфере дошкольного, начального общего, основного общего, среднего общего образования) (воспитатель, учитель)». [Электронный ресурс] Режим доступа: http://goo.gl/ow6qhg.

30. Гуманитарные технологии в вузовской образовательной практике: практика проектирования, анализа и применения: Учебное пособие / под общ. ред. Н.В. Бордовской. СПб.: Изд-во РГПУ им.А.И. Герцена, 2008. $636 \mathrm{c.}$

31. Современные технологии обучения в вузе (опыт НИУ ВШЭ в Санкт-Петербурге): Методическое пособие / под ред. М.А. Малышевой. СПб., 2011. 134 с.

32. Задорожный В.Н., Уваровская O.В., Баженов И.И. Обобщение опыта по использованию современных образовательных технологий в Сыктывкарском государственном университете // Перспективы науки. 2012. № 37 (37). С. 36-40.

33. Аниськин В.Н., К Кислова Н.Н., К Королев А.И., Шалифова О.Н. Моделирование и конструировние комплексного портфолио педагогических работников вуза для оценки эффективности их работы // Азимут научных исследований: педагогика и психология. 2015. № 4 (13). С. 11-14.

34. Сысоева Ю.Ю. Проектная методика в контексте компетентностного подхода при обучении иностранному языку студентов неязыкового вуза // Балтийский гуманитарный журнал. 2015. № 3 (12). С. 69-71. 
35. Гладких В.Г., Денисова О.В. Модель профессионального саморазвития будущего машиностроителя в проектном обучении // Азимут научных исследований: педагогика и психология. 2015. № 4 (13). С. 29-33.

36. Ясаревская О.Н. Проектная деятельность - один из способов развития коммуникативной компетенции студентов (на примере иностранного языка) // XXI век: итоги прошлого и проблемы настоящего плюс. 2015. T. 3. № 6 (28). C. 170-173.

37. Будник С.В. Портфолио как способ оценки исследовательской деятельности подростков в кружковой работе // Азимут научных исследований: педагогика и психология. 2014. № 1. С. 15-17.
38. Брыксина О.Ф., К Калинкина М.В. Дидактика высшей школы: инструментальное обеспечение современных педагогических технологий // Вестник Самарского государственного технического университета. Серия: Психолого-педагогические науки. 2014.№ 4 (24). C. 26-34.

39. Брыксина О.Ф., Тараканова Е.Н. Профессиональные сетевые сообщества как альтернатива формальной системе повышения квалификации педагогов // Актуальные задачи современной науки и образования: теоретические и прикладные аспекты Сборник научных трудов по материалам Международной научнопрактической конференции. 2015. С. 45-46.

\section{ICT ON-LINE RESOURSES AS A TOOL OF IMPLEMENTING THE FEDERAL STATE EDUCATIONAL STANDARD 44.03.01 PEDAGOGICAL EDUCATION} (c) 2016

M.A. Voronina, senior lecturer of the Chair of ICT in Education Samara State University of Social Sciences and Education, Samara (Russia)

Abstract. The article considers issues related to the use of the ICT in the modern education and analyzes the requirements of the federal state educational standards of primary, basic and higher education. The attention is focused on the need to develop the ICT competence at all levels of education. The concepts of using information and communication technologies in the classroom as well as the concept of «informatization of education» are analyzed.

A three-level model of the ICT competence of the teachers is described, which is stipulated by the professional teachers' standard. The article analyzes possibilities of interactive lectures supported by the social networks or the use of cloud technologies.

The article proposes the use of the case-study method in the virtual reality as a means of formation of the required competencies and increasing students' motivation. It analyzes the didactic potential of the pedagogical community network as a basis for lifelong learning. The experience of the use of the Internet community as a site of scientific pedagogical research is described. Videoconferences are proposed as a tool of teacher professional development. Google Hangouts application is evaluated as well.

The author draws a conclusion about the necessity for higher school teachers to use modern information technologies in the education process, which make it possible to transfer learning beyond the walls of the educational institution. Such education will comply with the Russian standard of living, and will be acceptable internationally.

Keywords: educational standards, bachelor, higher education, educational outcomes, educational technology, information and communication technologies, competences, innovation.

\section{УДК 37.013 .75}

\section{СРАВНИТЕЛЬНЫЙ АНАЛИЗ ПРЕДСТАВЛЕНИЙ УЧИТЕЛЕЙ САНКТ-ПЕТЕРБУРГА О РОЛИ И СУЩЕСТВЕННЫХ ХАРАКТЕРИСТИКАХ ПЕДАГОГИЧЕСКОЙ ДИАГНОСТИКИ}

(C) 2016

И.Ю. Гутник, кандидат педагогических наук, доцент кафедры педагогики

Российский государственный педагогический университет имени А.И. Гериена, Санкт-Петербург (Россия)

Аннотация. В статье представлен сравнительный анализ представлений учителей города Санкт-Петербурга из репрезентативной выборки и анализ мнений учителей одной из школ Санкт-Петербурга, имеющей многолетний опыт педагогической диагностики направленной на самоопределение ученика. В результате сравнительного анализа были получены выводы об осознании учителями необходимости применения педагогической диагностики в современном образовательном процессе. Было подтверждено понимание учителями важности каждодневного, близкого к интуитивному познанию своих учеников, зафиксировано, что имеющийся опыт сопровождения, базирующегося на педагогической диагностике, делает необходимым знание педагогом проблем и затруднений учеников. Был выявлен существенный дефицит знаний и умений у современного учителя, в области использования различных источников для получения информации об ученике. Было определено недостаточное понимание значимости применения качественных методов диагностики и методов аутентичной диагностики учителями современной школы, а так же недостаточное осознание важности учета мнения коллег и необходимости взаимодействия с ними, значимости коллективного, совместного выстраивания механизма диагностического сопровождения для всего коллектива школы. Была установлена закономерность в том, что обучение теории и практике педагогического диагностирования позволяет снимать многие проблемы в использовании педагогической диагностики - ее трудо- и времязатратность.

Ключевые слова: педагогическая диагностика, педагогическое сопровождение, поддержка, методы педагогической диагностики, рациональная и интуитивная педагогическая диагностика, наблюдение, анкетирование, беседа, портфолио, методы самодиагностики, самоопределение ученика, неформальные тесты. 